\title{
Hypotheses, neuroscience and real persons: The theme of the 10th International Conference on Philosophy, Psychiatry and Psychology
}

Psychiatry faces three exciting developments as we enter the 21 st century. First, and best recognised, are the dramatic advances in the neurosciences, notably in functional brain imaging and behavioural genetics, and the unique new insights that these are giving us into the causes of mental disorder.' Second, less dramatic but no less significant, are the innovative developments in person-centred psychiatric services in many parts of the world: drawing on multidisciplinary and multi-agency approaches, new models of service delivery are emerging that aim to put the real needs of real people, as individual service users and carers with unique needs and expectations, at the heart of mental health and social care (confer with the work of the US Presidential Commission, ${ }^{2}$ the World Health Organization, ${ }^{3}$ the World Psychiatric Association, ${ }^{4}$ and the UK Department of Health ${ }^{5}$ ). Third, least well recognised perhaps and certainly least expected, has been the emergence and rapid expansion of a new philosophy of psychiatry, not as an academic add-on to the subject, but as a close partner to the practice of psychiatry in both its research and service delivery aspects. ${ }^{6}$

It is these three developments in psychiatry that are reflected in the title of the 10th Annual Conference of the International Network for Philosophy and Psychiatry (INPP) that is being generously co-hosted by the South African Society of Psychiatrists (SASOP) in Sun City this year, namely 'Hypotheses, neuroscience and real persons'. This combination of themes underlines the ways in which hypotheses generated by the new philosophy of psychiatry are supporting developments both in the neurosciences and in person-centred psychiatric services. The fact that the conference is being held in South Africa furthermore reflects the leading role that SASOP has played in the new philosophy of psychiatry in general and in the International Network for Philosophy and Psychiatry in particular. The International Network was launched from Cape Town in 2002, on Heritage Day at the biennial meeting of SASOP. This event also coincided with the launch of SASOP's own Special Interest Group in Philosophy of Psychiatry (POP-SIG), which by the end of the meeting had already grown to be the second-largest special interest group in SASOP.

The new philosophy of psychiatry has shown similar rapid growth in many other countries around the world. There are now over 40 new national academic and professional organisations with large groups in North America (see editorial by Potter in this issue), the Netherlands, Germany, Italy and France. Like POP-SIG in SASOP, the Philosophy Special Interest Group in the Royal College of Psychiatrists in the UK has grown well beyond a 'special interest' group, being the second largest of all the sections of the College. There are also new sections for philosophy in both the World Psychiatric Association (WPA) and the Association of European Psychiatrists. The INPP was set up specifically to co-ordinate and support all these individual organisations.

Other important developments in building the academic infrastructure of the subject include the establishment of a quarterly international peer-reviewed journal, Philosophy, Psychiatry, \& Psychology, published by the Johns Hopkins University Press in the USA (now in its 14th year); new book series from the Netherlands, Germany, France, and Oxford University Press in the UK; and the establishment of several new professorial Chairs for the discipline, with corresponding research and teaching programmes, in a number of universities in the UK and Continental Europe. A notable recent addition to these has been the establishment of a doctoral scholarship in the Faculty of Philosophy of Oxford University (www.philosophy.ox.ac.uk), and the philosophy of psychiatry is now included in the Faculty's Development Plan. The significance of the contributions of South Africa to these academic developments resulted in the Oxford University Press book series, which is on International Perspectives in Philosophy and Psychiatry, being 'badged' with a South African multi-colour motif.

Most recently, in the UK, an Institute for Philosophy, Diversity and Mental Health has been launched within the Centre for Ethnicity and Health in the University of Central Lancashire Iwww.uclan. ac.uk/philosophyandmentalhealth). As Lord Patel of Bradford (Head of the Centre) and Chris Heginbotham (Director of the Institute with Bill Fulford) describe in their editorial in this issue, the Institute has been set up specifically to respond to the challenges arising from the developments in psychiatry noted above: its objectives are to take forward work that (i) draws particularly on philosophical research; and (ii) leads to developments in service delivery that are fully person-centred, particularly in being responsive to the wide diversity of individual service user and carer needs. The Institute also has an explicit commitment to develop its programme through two-way partnerships with colleagues in other parts of the world, and to this end it has generously agreed to act as academic host for the International Network for Philosophy and Psychiatry.

More remarkable even than the rate and scope of these academic developments, however, has been the speed with which the resources of philosophy are already being translated into practical developments in the field. In relation to the neurosciences, joint programmes of work between brain imaging 
researchers, philosophers of mind and those with personal experience of mental disorder have already produced important new hypotheses. 7 Analytic philosophy, in the work of the American psychiatrist and philosopher, John Sadler, is providing a detailed understanding of the role of values in psychiatric diagnosis that will inform current revisions of both the American Psychiatric Association's Diagnostic and Statistical Manual and the World Health Organization's International Classification of Diseases. ${ }^{8}$

Phenomenology, too, has a vital role in relation to the neurosciences. There is of course a clear historical precedent for this, particularly in the work of the first philosopher-psychiatrist, Karl Jaspers, ${ }^{9}$ whose General Psychopathology was crucial to the foundations of modern scientific psychiatry. But phenomenology is no less important today, with innovative contributions from each of its several strands: in addition to those noted by Giovanni Stanghellini and Cristian Muscelli in their editorial in this issue, examples include new research drawing on the phenomenologies respectively of Martin Heidegger, ${ }^{10}$ Jean-Paul Sartre ${ }^{11}$ and Maurice Merleau-Ponty. ${ }^{12}$ The importance of such work has been emphasised by some of those working at the leading edge of the neurosciences. The Austrian psychiatrist and phenomenologist, Michel Musalek, has shown the value of phenomenological work to neuroscientific research on delusion. ${ }^{13}$ The American neuroscientist and psychiatrist, Nancy Andreasen, has recently warned that unless psychiatry rediscovers phenomenology, the neurosciences risk becoming a 'silent spring'. ${ }^{14}$

Other important work relevant to the sciences underpinning psychiatry, includes work in the philosophy of science of the British philosopher of psychiatry, Tim Thornton, on the irreducible role of individual judgement both in science itself and in its applications in day-to-day practice. ${ }^{15}$ As Thornton describes in his editorial in this issue, these insights from the philosophy of science, by providing a deeper understanding of such concepts as 'clinical judgement', could make a crucial contribution to the ways in which findings from the neurosciences are applied not only in treatment but also in diagnosis. There have also been some innovative studies on the links between subjective aspects of anxiety and its physiological basis, by the Dutch philosopher and psychiatrist, Gerrit Glas. ${ }^{16}$

In relation to service development, an example of a particularly vigorous 'philosophy into practice' growth area of the new philosophy of psychiatry is what has become known as 'valuesbased practice'. Derived from theoretical ideas in a branch of Oxford analytic philosophy, ${ }^{17}$ and combined with the resources of phenomenology ${ }^{18}$ and of the social sciences, ${ }^{19}$ values-based practice offers a new approach, based on learnable clinical skills, for working with complex and conflicting values in health care decision-making. A training manual in values-based practice for mental health was launched by the UK Minister of State for
Mental Health, Rosie Winterton, at a conference in London in $2004,{ }^{20}$ and has subsequently become the basis for a number of national policy, training and service development initiatives in mental health and social care in the UK. ${ }^{21}$ Values-based practice in psychiatry has been supported internationally through the World Psychiatric Association, including its Institutional Program for Psychiatry for the Person as described by Juan Mezzich, the President of the WPA, in his editorial in this issue, and through a number of its member organisations. Corresponding values-based practice approaches in medicine are currently being taught at Warwick Medical School in the UK in partnership with the University of Pretoria Medical School.

Other areas of successful translation of philosophy into practice include work by the Oxford philosopher, Rom Harré, and the American psychologist, Steven Sabat, drawing on discursive philosophy to produce improved communication skills for professionals and carers working with people with dementia; ${ }^{22,23}$ work by the Dutch philosopher, Guy Widdershoven, using hermeneutic methods also with people with dementia; ${ }^{24}$ and combined philosophical and social science methods developed by the British psychiatrists, Jacinta Tan, Tony Hope and Ann Stewart, to explore problems of decision-making in young women with anorexia nervosa. ${ }^{25}$ Even logic has a place! New variables derived from Frege's logic of relations have been shown to provide unique new insights into tracking recovery from mental disorder. ${ }^{26}$

The successful translation of philosophy into practice has been fuelled by a strong collaborative spirit that has been evident internationally. Nancy Potter in her editorial in this issue describes similarly the collaborative work at the bedside between psychiatrists, philosophers and patients. She urges congruently for even more effective collaboration through the innovative use of blogs and podcasts. This is particularly significant. Philosophy is often and sometimes rightly perceived as being a backwardlooking discipline. Certainly, we have much to learn from the history of ideas in psychiatry. But this work underlines the importance of rigorous philosophical scholarship in helping to explore and anticipate the ways in which the ever-accelerating rate of technological advance will impact, for good or ill, on the complex challenges of mental health.

It is no coincidence that the new philosophy of psychiatry has developed so strongly as an international discipline. Psychiatry is perhaps the most complex of medical disciplines: it faces the twin challenges of research on the brain, certainly the most complex mechanism known, and of delivering services that are fit for purpose in meeting the hugely diverse needs of those with mental distress and disorder. Nothing short of the rich resources of the many traditions of thought and practice represented by different cultures around the world will be needed to meet this 
twin challenge. Nancy Andreasen, again, has made this point specifically in relation to the neurosciences, noting by way of example the importance of the continuing phenomenological tradition of Continental Europe as a resource for the neurosciences as they have developed in the more positivist traditions of Britain and North America. ${ }^{27}$ In relation to service delivery, the lesson of history is that the worst abuses of psychiatry occur, not through deliberate malpractice, but through psychiatry, in any local context, becoming fixed on what the German historian of psychiatry, Paul Hoff, has called a 'single message mythology'. ${ }^{28}$

It is in the international arena, in particular, that South Africa has a key role to play in the further development of the philosophy of psychiatry as a fully international discipline. So far, although the new discipline is well represented on the practice side of psychiatry in most parts of the world, notably through the tremendous support of the WPA, the research base of the subject has thus far drawn mainly on the philosophies of Western Europe and North America. Rich and productive as these philosophies have proven to be, they represent only a quarter of the world, and there are clear indications that other traditions, particularly the more praxis-based philosophies of Africa ${ }^{29-31}$ and Asia, ${ }^{32-34}$ could prove even more fruitful. The unique mix of cultures and races that make up South Africa, and the historically unique achievement of Mr Mandela's 'rainbow nation' in bringing them together as a coherent nation, thus provides a crucible for the future expansion of the philosophy of psychiatry, building on secure scientific foundations, but encompassing as much the traditions of nonWestern as of Western thought and practice.

Mr Mandela's rainbow nation is the basis also of a deeper reason for the special significance of South Africa in the new philosophy of psychiatry. This has to do with what is perhaps the greatest challenge to everyone concerned with mental health, whether as professionals or as service users, as we enter the 21 st century, namely the continued stigmatisation of the field and the consequent grossly defective services and other abuses of human rights to which this leads, as illustrated by Kamlesh Patel and Chris Heginbotham in their editorial in this issue. There are no doubt many and complex causes for this stigmatisation. ${ }^{35}$ But as one of us has argued elsewhere, it has many of the features of a form of racism. ${ }^{36}$ This is where the example of South Africa provides a crucial lead. For under the leadership of Mr Mandela, South Africa achieved, for probably the first time in history, a political revolution without the extensive violence and destruction that are known to go with it - at the heart of which has been the replacement of racism with a core value of respect for diversity.

It is this same core value of respect for diversity, then, that is at the heart of the mission statement of the International Network for Philosophy and Psychiatry. In full, the first aim of the International
Network is 'to support educational, research, policy and service development initiatives in mental health that are based on valuing individual and cultural differences and respecting diversity' I www. inpponline.org). It was this shared core value that led to the International Network being launched originally from South Africa. It is this shared cored value, too, that is reflected in the activities of the Network being badged with the South African multi-colour motif. And it is this shared core value, finally, that makes it so significant that this year's conference of the International Network, bringing together as it does new hypotheses, the neurosciences and real people, should be held in South Africa and co-hosted by the South African Society of Psychiatrists.

\section{W (Werdie) van Staden}

Department of Psychiatry

University of Pretoria, and

Weskoppies Hospital

Pretoria

\section{K W M (Bill) Fulford}

Department of Philosophy and Medical School University of Warwick,

Departments of Psychiatry and Philosophy

Oxford University,

Institute for Philosophy, Diversity and Mental Health

University of Central Lancashire, and

Department of Health

London

1. Zachar P, Kendler KS. Psychiatric disorders: a conceptual taxonomy. Am J Psychiatry 2007; 164: 557-565

2. US Presidential Commission on Mental Health. Achieving the Promise: Transforming Mental Health Care in America. Final report. Rockville: US Department of Health and Human Services, 2003.

3. World Health Organization. Mental health action plan for Europe: facing the challenges, building solutions. Helsinki, 12-15 January 2005.

4. Mezzich J, Salloum IM. Towards innovative international classification and diagnostic systems: ICD-1 1 and person-centered integrative diagnosis. Acta Psychiatr Scand (in press).

5. Department of Health. Mental Health: New Ways of Working for Everyone. London: Department of Health, 2007

6. Fulford KWM, Morris KJ, Sadler JZ, Stanghellini G, eds. Past Improbable, Future Possible: the renaissance in philosophy and psychiatry. In: Nature and Narrative: an Introduction to the New Philosophy of Psychiatry. Oxford: Oxford University Press, 2003: $1-41$

7. Hoerl C. Understanding, explaining, and intersubjectivity in schizophrenia. Philosophy, Psychiatry, \& Psychology 2001; 8: 83-88

8. Sadler JZ. Values and Psychiatric Diagnosis. Oxford: Oxford University Press, 2005

9. Jaspers K. Algemeine Psychopathologie. Berlin: Springer-Verlag, 1913. Trans. J Hoenig, MW Hamilton (1963). Baltimore: Johns Hopkins University Press, 1997.

10. Bracken P. Trauma: Culture, Meaning and Philosophy. London: Whurr Publishers, 2002.

11. Morris KJ. The phenomenology of body dysmorphic disorder: a Sartrean analysis. In: Fulford KWM, Morris KJ, Sadler JZ, Stanghellini G, eds. Nature and Narrative: An Introduction to the New Philosophy of Psychiatry. Oxford: Oxford University Press, 2003: 270-274

12. Philpott MJ. A phenomenology of dyslexia: the lived-body, ambiguity, and the breakdown of expression. Philosophy, Psychiatry, \& Psychology 1998; 5: 1-20, 3336 .

13. Musalek M. Meanings and causes of delusions. In: Fulford KWM, Morris KJ, Sadler JZ, Stanghellini G, eds. Nature and Narrative: An Introduction to the New Philosophy of Psychiatry. Oxford: Oxford University Press, 2003: 155-169. 


\section{editorials}

14. Andreasen NC. DSM and the death of phenomenology in America: an example of unintended consequences. Schizophr Bull 2007; 33: 108-112.

15. Thornton T. Essential Philosophy of Psychiatry. Oxford: Oxford University Press (in press).

16. Glas G. Anxiety - animal reactions and the embodiment of meaning. In: Fulford KWM, Morris KJ, Sadler JZ, Stanghellini G, eds. Nature and Narrative: An Introduction to the New Philosophy of Psychiatry. Oxford: Oxford University Press, 2003: 231-249.

17. Fulford KWM. Moral Theory and Medical Practice. Cambridge: Cambridge University Press, 1989/1995/1999.

18. Stanghellini G. Deanimated Bodies and Disembodied Spirits. Essays on the Psychopathology of Common Sense. Oxford: Oxford University Press, 2004

19. Colombo A, Bendelow G, Fulford KWM, Williams S. Evaluating the influence of implicit models of mental disorder on processes of shared decision making within community-based multi-disciplinary teams. Soc Sci Med 2003; 56: 1557-1570.

20. Woodbridge K, Fulford KWM. Whose Values? A Workbook for Values-based Practice in Mental Health Care. London: Sainsbury Centre for Mental Health, 2004.

21. Department of Health (40339). The Ten Essential Shared Capabilities: A Framework for the Whole of the Mental Health Workforce. London: Sainsbury Centre for Mental Health, National Health Service University, and NIMHE (National Institute for Mental Health England), 2004

22. Sabat SR, Harré R. The Alzheimer's disease sufferer as semiotic subject. Philosophy, Psychiatry, \& Psychology 1997; 4: 145-160.

23. Sabat SR. The Experience of Alzheimer's Disease: Life Through a Tangled Veil. Oxford: Blackwell Publishers. 2001.

24. Widdershoven G, Widdershoven-Heerding I. Understanding dementia: a hermeneutic perspective. In: Fulford KWM, Morris KJ, Sadler JZ, Stanghellini G, eds. Nature and Narrative: An Introduction to the New Philosophy of Psychiatry. Oxford: Oxford University Press, 2003: 103-112.
25. Tan JOA, Hope T, Stewart A. Anorexia nervosa and personal identity: The accounts of patients and their parents. Int J Law Psychiatry 2003; 26: 533-548.

26. Van Staden CW, Fulford KWM. Changes in semantic uses of first person pronouns as possible linguistic markers of recovery in psychotherapy. Aust N ZJ Psychiatry 2004; 38: 226-233.

27. Andreasen NC. Changing concepts of schizophrenia and the ahistorical fallacy. Am J Psychiatry 1994; 151: 1405-1407.

28. Hoff P. Die psychopathologische Perspektive. In: Bormuth M, Wiesing U, eds. Ethische Aspekte der Forschung in Psychiatrie und Psychotherapie. Cologne: Deutscher Aerzte-Verlag, 2005: 71-79

29. Hallen B, Sodipo J, Olubi. Knowledge, Belief and Witchcraft: Analytic Experiments in African Philosophy. Stanford, Calif.: Stanford University Press, 1997

30. Okasha A, Maj M, eds. Images in Psychiatry: An Arab Perspective. World Psychiatric Association. Egypt: Scientific Book House, 2001

31. Coetzee PH, Roux APJ, eds. Philosophy from Africa. 2nd ed. Cape Town: Oxford University Press, 2002

32. Yuasa Y. The Body. Toward an Eastern Mind-Body Theory. New York: State University of New York Press, 1987

33. Yamaguchi, I. Ki also leibhaftige Vernuft, Beitrag zur interkulturellen Phänomenologie der Leiblichkeit. München: Fink, 1997.

34. Depraz N. Putting the époché into practice: schizophrenic experience as illustrating the phenomenological exploration of consciousness. In: Fulford KWM Morris KJ, Sadler JZ, Stanghellini G, eds. Nature and Narrative: An Introduction to the New Philosophy of Psychiatry. Oxford: Oxford University Press, 2003: 187-198

35. Sartorius N. Psychiatry and society. Die Psychiatrie 2004; 1: 36-4 1.

36. Fulford KWM, Radden J. An internal racism. Bioethics 2002; 16(5): III-VIII. 